\title{
Pairing of Intelligence Design Concept Method and Kano Model for Product Development
}

\author{
Mr. P.S.Senthil Kumar', Dr. S.Balasubramanian ${ }^{2}$, Dr. R.K.Suresh ${ }^{3} \&$ \\ Dr. S.Arularasu ${ }^{4}$
}

\begin{abstract}
The deployment of scientific approach to customers' voice by means of customer science to achieve a good product development process. This model means implementing Customer Kano Model for turning the design perception into a precise knowledge as more creative activities from the hidden knowledge of designing using statistical science. The model has been applied to product design process and the results obtained are shown.

Keywords: Customer Kano Science, Automobile, CS-IDCM,Need model, Likerts scale, Concept car.

${ }^{1}$ Mr. P.S.Senthil Kumar, Research Scholar, Faculty of Mechanical Engineering, Anna University Coimbatore, Tamil Nadu, India.

${ }^{2}$ Dr. S.Balasubramanian, Research Supervisor,Anna University Coimbatore, Tamil Nadu, India. (email: s_balasubramanian@ rediffmail.com)

${ }^{3}$ Dr. R.K.Suresh, Principal, PA College of Engineering and technology, Pollachi, Tamil Nadu, India

${ }^{4}$ Dr. S.Arularasu, Professor, Department of Production Engineering, Government College of Technology, Coimbatore, Tamil Nadu, India
\end{abstract}




\section{INTRODUCTION}

Automotive product development is an innovative and ongoing process which is taking a greater chance of change from functional quality to product oriented development that needs improvement quiet often considering the market and the demand from the customer. At this juncture, it is essential to formulate scientific approaches to accurately grasp and reflect on the product based on the need of the customer or consumer. The product planning department in association with the customers' whims should provide the designing team with a crystal clear product concept. This has paved the way for concept cars that is very much required for the present urban vehicle population and to curb pollution.

Hidden knowledge is termed as implicit knowledge and precise knowledge is termed as explicit knowledge. In this paper, a conception support method for developing strategic product is applied and is reflected in automotive exterior aesthetics and interior ergonomics for a concept car. A specific commercialization study was conducted to have the feel of academic and industrial experts for concept cars that can be used in urban and densely populated cities. This statistical scientific approach and customer science method is applied to make the product development as more explicit oriented knowledge tuning from implicit knowledge needed by the customers. As an application of this research, this model to product design process is applied and obtained results are shown.

\section{ISSUES IN MARKETING, SALES, PRODUCT PLANNING} AND DESIGN

Customer oriented business Management is followed in the developing countries to grasp the important desires and requirements, expectations from the customers and reflect their wishes in future product development. Designers take these into consideration and proceed with product development using hidden knowledge processes. The performance is measured by sales force and their input for the development team. The implicit knowledge gathered by the sales force may not be sufficient for the future product development and hence a scientific approach is taken as a model for bringing out better results with Kano model, Tontinis need satisfaction and Likert's scale. This paper will use CS-IDCM for the future product development. 


\section{SCIENTIFIC CUSTOMER ANALYSIS}

The ultimate goal of every company is to supply products that satisfy customers and continuous growth. This is continued in accordance with the value of customers in addition to the life stage and life pattern of individual customer. A visionary product development method is essential to bring increased value in current problems in customer needs. For new product development in future, it is essential to supply desirable products before customers desire them. Proposal of Customer Science makes it possible to finalize customer desires. Attractive products development new business processes is the desirable want for success.

Figure 1 shows the customers voice (implicit knowledge) is translated into lingual knowledge

(Concept) and then into technical language as explicit knowledge (Technical drawings). This approach will make uncertain business processes more accurate, increasing success rates and decreasing possibilities of failure.

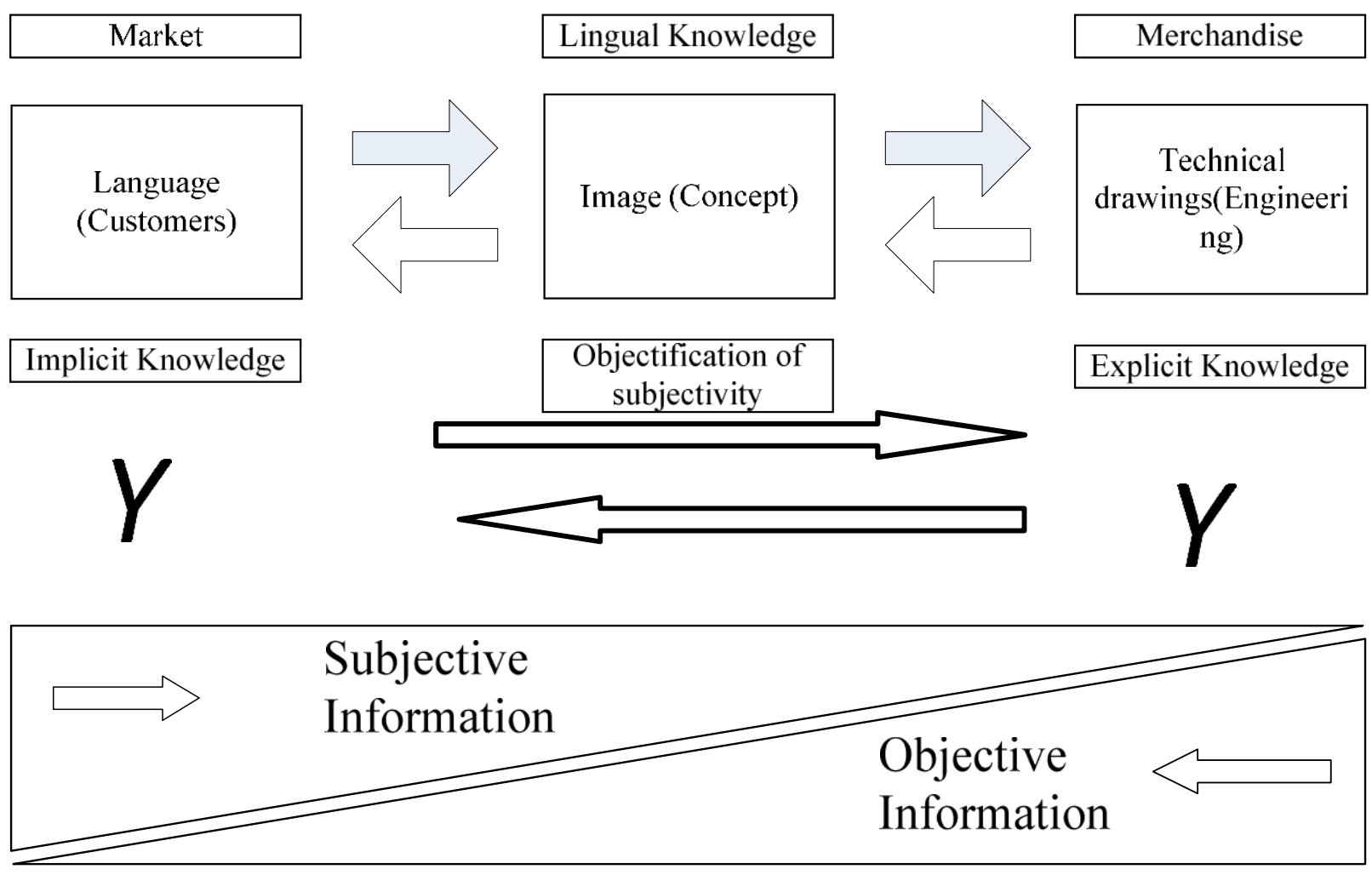

Figure 1: Schematic drawing of Customer Science Principle 


\section{INTELLIGENT DESIGN CONCEPT METHOD-CS-ID}

There are three methods that link the process of product development process and determine the suitable method to convert implicit knowledge to explicit knowledge. The addition in the first method goes well with the Kano Model and satisfaction and need requirements are mapped. The following paragraphs describe about the three methods which form the basis for the product development process.

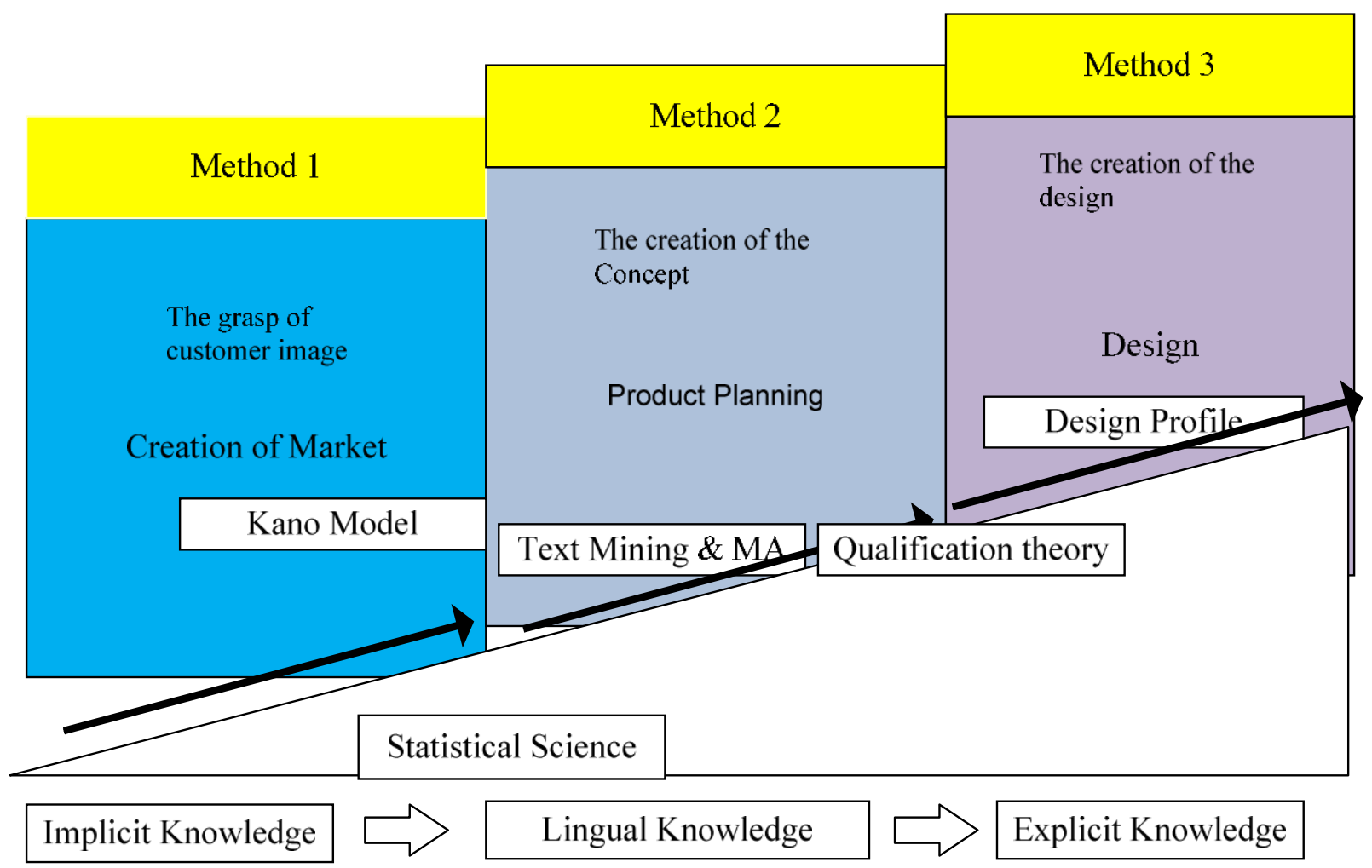

Figure 2: CS-IDCM.

Method 1: In this method the sense and sensitivity of the customer is clearly indicated that combines and changes implicit (Hidden) knowledge to explicit (Precise) knowledge. Here the designers use the customer data science and Kano model is very effective.

Method 2: In this method the product concept is created with the need of the customers. The analysts and designers create the product concept based on the customer inputs and use of text mining and qualification theory is more effective.

Method 3: In this method the creation of design improves generation of new ideas that is useful for the development process and profile design. Analysis process supports idea generation and is highly effective with multivariate statistical analysis and qualification theory. 
By combining all three methods, the product development process can be expressed from implicit knowledge to explicit knowledge that is from hidden to precise solutions by analysis oriented technology in the automotive design engineering sector.

\section{APPLICATION OF CS-IDCM METHOD}

The present issue for creating attractive vehicles is related to design that is of a concept support method for designers (12) which contribute to the innovation of design process. This is especially in the case of concept vehicle design suitable for urban cities and satisfying both the exterior aesthetics and ergonomics of interior for a concept car. This paper focuses on the designing of small concept cars which has troubled designers. In this the application of CS-IDCM for the product development of a new model is presented.

$\mathbf{1}^{\text {st }}$ Step: Application of Kano model with the formation of questionnaire and to find out the customer response, satisfaction and need for the model. The model proposed by Kano is an effective tool for assessment based on the following principles ( Berger et al., 1993):

- Invisible ideas about quality can be made visible with a clear requirement on a performance versus satisfaction map.

- The one dimensional customer requirement: For example better car mileage than worse.

- The Must-be requirement: dissatisfaction takes place when one of the functions of the product fails but still can manage-For example: An air-conditioner in the car.

- The attractive requirement: When the customer is most satisfied with the product when it is functional and not dissatisfied even if the product is less functional. For example- A tape recorder in the car.

- The indifferent Requirement: when customers are indifferent to the improvement of the product. For example-Cigarette lighter in a car is rarely used to light cigarette.Now it is more used as power supply device for small electric device.

Table 1: Kano model classification of customer needs

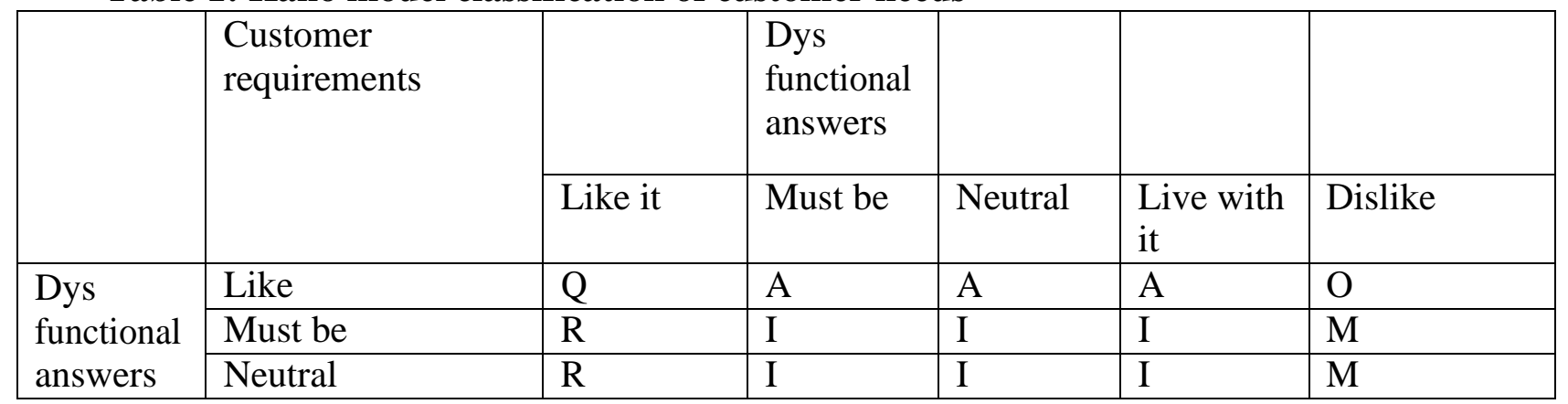




\begin{tabular}{|l|l|l|l|l|l|l|}
\hline & Live with it & R & I & I & I & M \\
\cline { 2 - 6 } & dislike & R & R & R & R & Q \\
\hline
\end{tabular}

A- Attractive Q-Questionable R-Reverse M-

Must -be O-One dimensional

$2^{\text {nd }}$ Step: Since there are limitations in Kano model, an improvement was added which was proposed by Tontini ( Tontini,2003b). Firstly tontine added an index measuring the reverse degree of the requirement. Secondly, scores ranging from -2 to +2 were proposed (score -2 for answering 'This would be a major problem for me and I can't accept it" and +2 for "This would be very helpful to me"). These ratings were used to calculate new indicators.

Following Tontini's proportion a matrix formulation and graphical representation is suggested of the requirements. The matrix formulation based on Kano model is implemented on the real case study, given in the following section.

\section{Table 2:Need assessment and codification}

\begin{tabular}{|l|l|l|}
\hline S1 no & Codification & Needs \\
\hline 1 & N1 & Use of rubber components as exteriors \\
\hline 2 & N2 & Minimum expenses for surface coatings \\
\hline 3 & N3 & $\begin{array}{l}\text { Utilization of outer surface for solar panels as a power supply } \\
\text { device }\end{array}$ \\
\hline 4 & N4 & Length of the car too long so stiffness weakens \\
\hline 5 & N5 & More smaller the better for urban ride \\
\hline 6 & N6 & Dimensions of the cars need to be according to the age \\
\hline 7 & N7 & Enough of two persons for a ride with a limited luggage capacity \\
\hline 8 & N8 & Zero pollution less weight concept cars \\
\hline 9 & N9 & Easy drive with less turning radius \\
\hline 10 & N10 & Seating posture with high rise seats \\
\hline 11 & N11 & $\begin{array}{l}\text { Interior need not be so expensive but comfortable-on board } \\
\text { comfort }\end{array}$ \\
\hline 12 & N12 & Easy of maintenance \\
\hline
\end{tabular}

\section{The assessment was done in two phases}

- Assessment study for the age group of 18 to 38

(Includes students, working men, women, commuters in cities)

- Assessment study for the age group 39 and above.

(Includes professionals and others-both vehicle owners and non-owners) As a consequence, two different Kano questionnaires were prepared. Both had the same Kano questions (functional and dys functional). 


\section{$3^{\text {rd }}$ Step: Needs assessment}

Data collection took place based on the Kano questionnaire from two different groups aged between 18 and 38 and aged between 39 and above till 58. Five hundred questionnaires were distributed but there were only 348 who responded for the questionnaire. The remaining 152 questionnaires were not answered properly and many were half done. Some of them took the questionnaire home and never returned back.

Based on the data collection, a matrix of the order (348x12) was obtained having 348 rows for respondents and 12 columns for the requirements. Two matrices are formulated that is one for Functional requirements/answers and second for Dys functional matrix.Xij and Yij respectively are the answers for the Dys functional and functional questions. Here the Likerts scale is adopted for the purpose of giving positive and negative scores according to the answers.

(Yij): Functional Matrix

$$
F I=\frac{\sum \substack{i=1 \\ Y i j>0}}{2 N}
$$

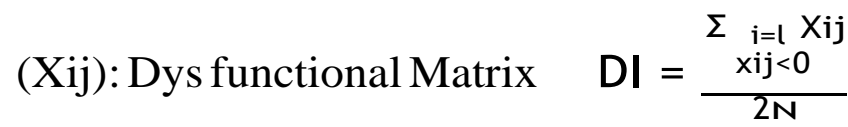

(Rij): Reverse Score

$$
R I=\frac{\sum_{\substack{i=1 \\ Y i j<0}}^{2 N}}{2 N}
$$

$\mathrm{S} \mathrm{I}=\frac{\sum \text { degree of satisfaction with existance }}{\text { Number of Responses } \mathrm{X}}$ (only the $>0$ at the functional questions)

$\mathrm{D} \mathrm{I}=\frac{\sum \text { degree of dissatisfaction with inexistence }}{\text { number of responses } \mathrm{X} 2}$ (only at the $<0$ at the dysfunctional question)

$\mathrm{R} I=\frac{\sum \text { Number of dissatisfaction with existance }}{\text { Number of responses } \mathrm{X} 2}($ Only at the $<$ at the functional questions )

$\mathrm{N}$ needs $\mathrm{j}$

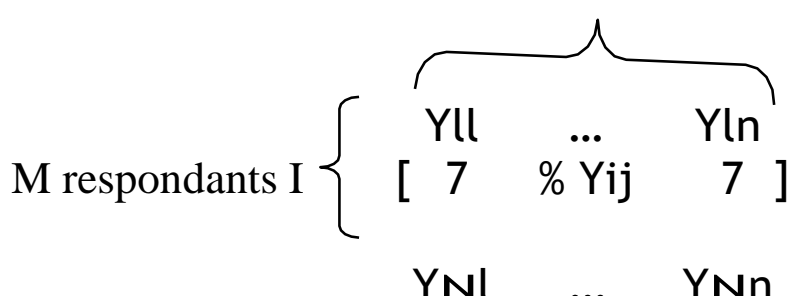

(Yij): Functional Matrix 


\section{$\mathrm{N}$ needs j}

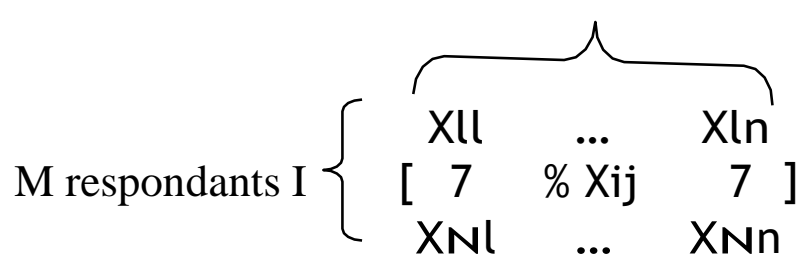

(Xij): Dys Functional Matrix

Functional Question:

Q: You are provided with a concept car that has appealing exterior aesthetics and on board comfort interior, how do you feel?

1. This would be excellent to me +2

2. This would be an added requirement for me +1

3. This would not affect me 0

4. This would have minor inconvenience in other areas .I can live it that way -1

5. This would be a major problem for me and I can't accept it. -2

Dysfunctional questions:

Q: You are provided with a concept car that does not have appealing exterior aesthetics and does not have on board comfort interior, how do you feel?

1. This would be excellent to me +2

2. This would be an added requirement for me +1

3. This would not affect me 0

4. This would have minor inconvenience in other areas .I can live it that way -1

5. This would be a major problem for me and I can't accept it. -2

The three coefficients were calculated and data gathered through the questionnaire were tabulated.

Table 3: SI,DI and RI for the concept car need case

\begin{tabular}{|l|l|l|l|l|l|l|l|l|l|l|l|l|}
\hline Needs, Codes & N1 & N2 & N3 & N4 & N5 & N6 & N7 & N8 & N9 & N10 & N11 & N12 \\
\hline SI & 0,62 & 0,83 & 0,76 & 0,85 & 0,78 & 0,17 & 0,52 & 0,63 & 0,79 & 0,55 & 0,71 & 0,73 \\
\hline DI & 0,37 & 0,31 & 0,42 & 0,41 & 0,32 & 0,05 & 0,52 & 0,30 & 0,63 & 0,38 & 0,49 & 0,33 \\
\hline RI & 0,04 & 0,04 & 0,02 & 0,01 & 0,02 & 0,30 & 0,08 & 0,02 & 0,02 & 0,05 & 0,00 & 0,05 \\
\hline
\end{tabular}

Kano Model questionnaire identified the requirement of each through the identified groups. In this N6 is a reverse need and hence this need is taken for consideration. Further again the need requirement is found out by changing the score of N6 only. The following table depicts the same. 
Table 4:Reverse needs results

\begin{tabular}{|l|l|l|l|l|l|l|l|l|l|l|l|l|}
\hline Needs, Codes & N1 & N2 & N3 & N4 & N5 & N6 & N7 & N8 & N9 & N10 & N11 & N12 \\
\hline SI & 0,62 & 0,83 & 0,76 & 0,85 & 0,78 & $\mathbf{0 , 1 7}$ & 0,52 & 0,63 & 0,79 & 0,55 & 0,71 & 0,73 \\
\hline DI & 0,37 & 0,31 & 0,42 & 0,41 & 0,32 & $\mathbf{0 , 0 5}$ & 0,52 & 0,30 & 0,63 & 0,38 & 0,49 & 0,33 \\
\hline RI & 0,04 & 0,04 & 0,02 & 0,01 & 0,02 & $\mathbf{0 , 3 0}$ & 0,08 & 0,02 & 0,02 & 0,05 & 0,00 & 0,05 \\
\hline
\end{tabular}

Thus a graph is drawn with the $\mathrm{Y}$ and $\mathrm{X}$ values derived from the functional and dys functional equations. Finally a map is available for decision makers giving them some important guidelines in order to define design priorities. This map would clearly show the major needs required to be satisfied. Based on the scores SI, DI and RI are marked in the graph.

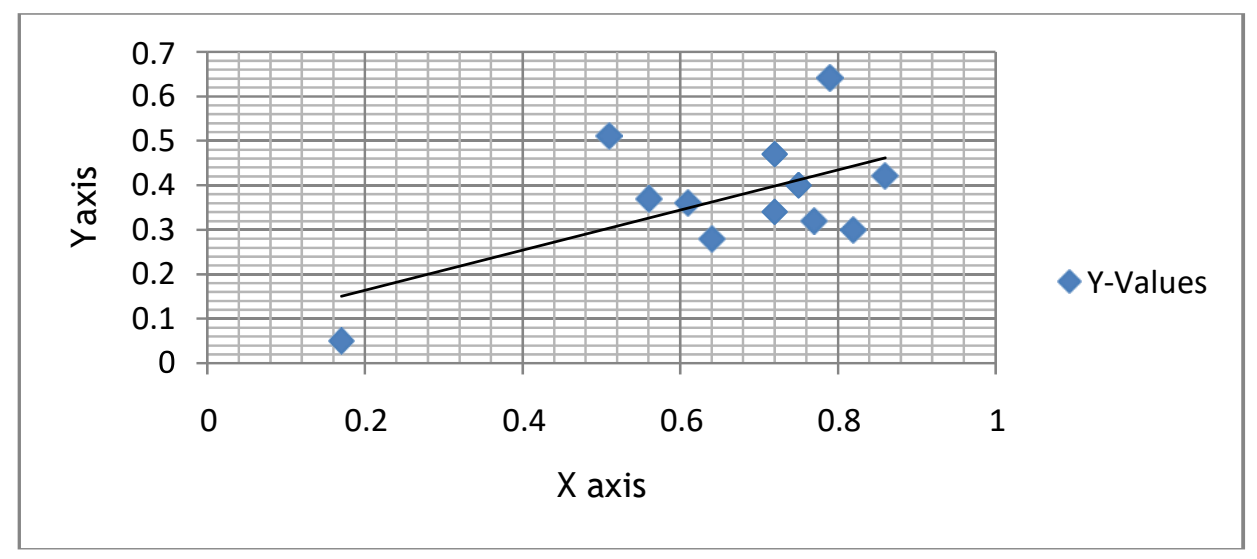

Figure 3:Representation of values of SI and DI

Experimental study for other group of elderly people:

The following data were calculated based on the other group of people aged between 2958 and is tabulated.

Table 5:SI,DI,RI results of concept car elderly people group

\begin{tabular}{|l|l|l|l|l|l|l|l|l|l|l|l|l|}
\hline Needs, Codes & N1 & $\mathbf{N 2}$ & $\mathbf{N 3}$ & $\mathbf{N 4}$ & $\mathbf{N 5}$ & $\mathbf{N 6}$ & $\mathbf{N 7}$ & $\mathbf{N 8}$ & $\mathbf{N 9}$ & $\mathbf{N 1 0}$ & $\mathbf{N 1 1}$ & $\mathbf{N 1 2}$ \\
\hline SI & 0,67 & 0,87 & 0,74 & 0,92 & 0,76 & 0,66 & 0,60 & 0,72 & 0,86 & 0,65 & 0,66 & 0,62 \\
\hline DI & 0,45 & 0,32 & 0,25 & 0,39 & 0,29 & 0,34 & 0,47 & 0,33 & 0,66 & 0,37 & 0,53 & 0,22 \\
\hline RI & 0,08 & 0,03 & 0,08 & 0,03 & 0,02 & 0,07 & 0,12 & 0,04 & 0,04 & 0,08 & 0,05 & 0,09 \\
\hline
\end{tabular}




\section{A graph is drawn for the data:}

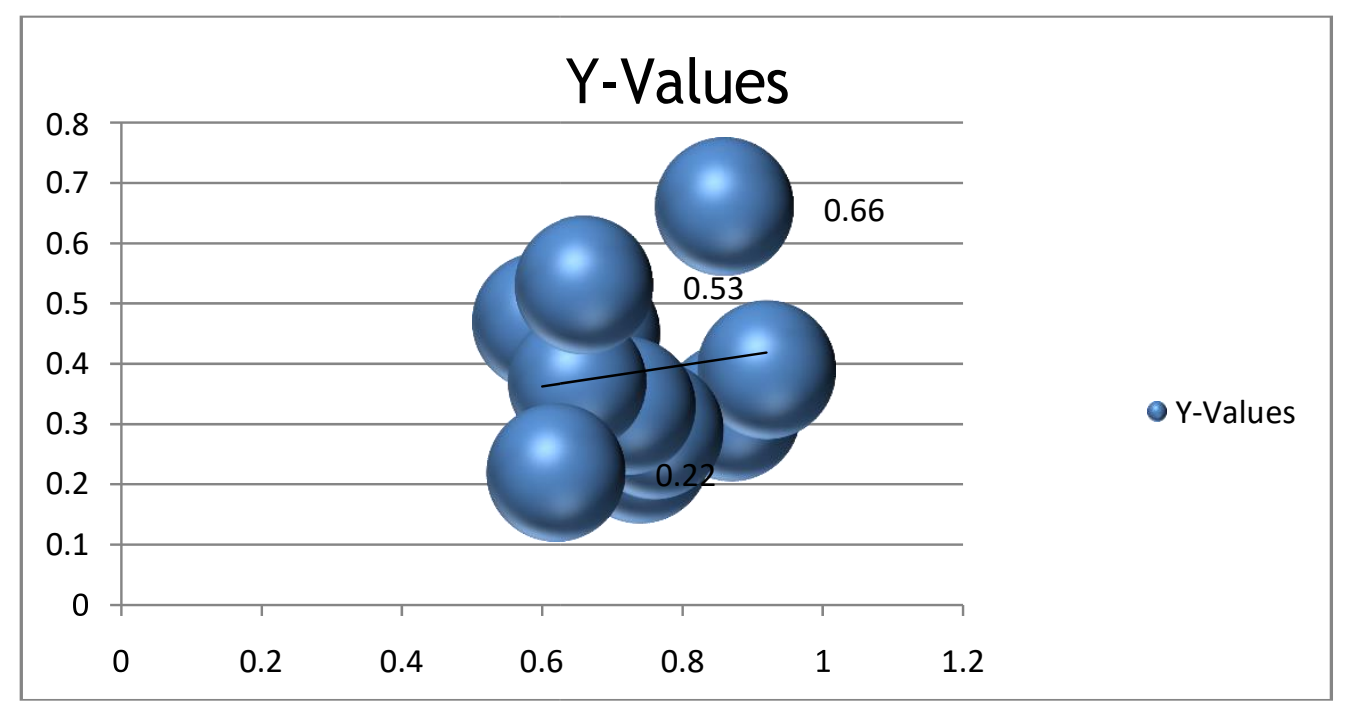

Figure 4:Representation of values of SI and DI

The needs assessment was done with the tool Kano model and hence the attractive needs have been identified for the purpose of examining the aesthetics exterior and on board comfort interior of concept cars. The CS-IDCM method is used for the same.

The results that are obtained from the Kano Model are used in Customer science Package design concept support method.

\section{APPLICATION}

The grasp of customers' voice is transformed into an explicit knowledge with the help of this method. A detailed study was undergone in the exteriors and interiors of the Indian cars and the results of the comparison are depicted in the following table. The suitability of the concept cars lie in the urban and population centered cities and space. Mostly all respondents have an option to have concept cars and less travel, more comfort and safety along with ergonomics. Thus a new method is taken and the product development is

analyzed for the better concept model that creates a good vehicle for urban dwellers. The ultra compact dimensions are suggested as results for this method and this paper.

The concern for exterior aesthetics is predominantly related to design of exterior and in which the interior space or comfort is determined. So the exterior design will help the interior on board comfort feasible. 


\section{The creation of the concept:}

By applying Package design concept support method, optimal interior space and on board comfort is adjudged by the ratio of exterior with respect to the aesthetic evaluation survey. Analysis of the survey results has made us to understand the relationship between exterior aesthetics and interior comfort and ergonomics. By using text mining the customers feel was extracted and a free opinion comment was collected for reference data. Based on the customers input, there is a demand for concept small cars and less weighing cars that can be used for the urban dwellers and in populated cities.

The following figure states the results of customer preferences for concept cars and interiors dimensions as of now in the automobiles. Free opinion data like the leg room should be better, roof is too high, safety is moderate, unladen weight is too much, view is difficult etc.

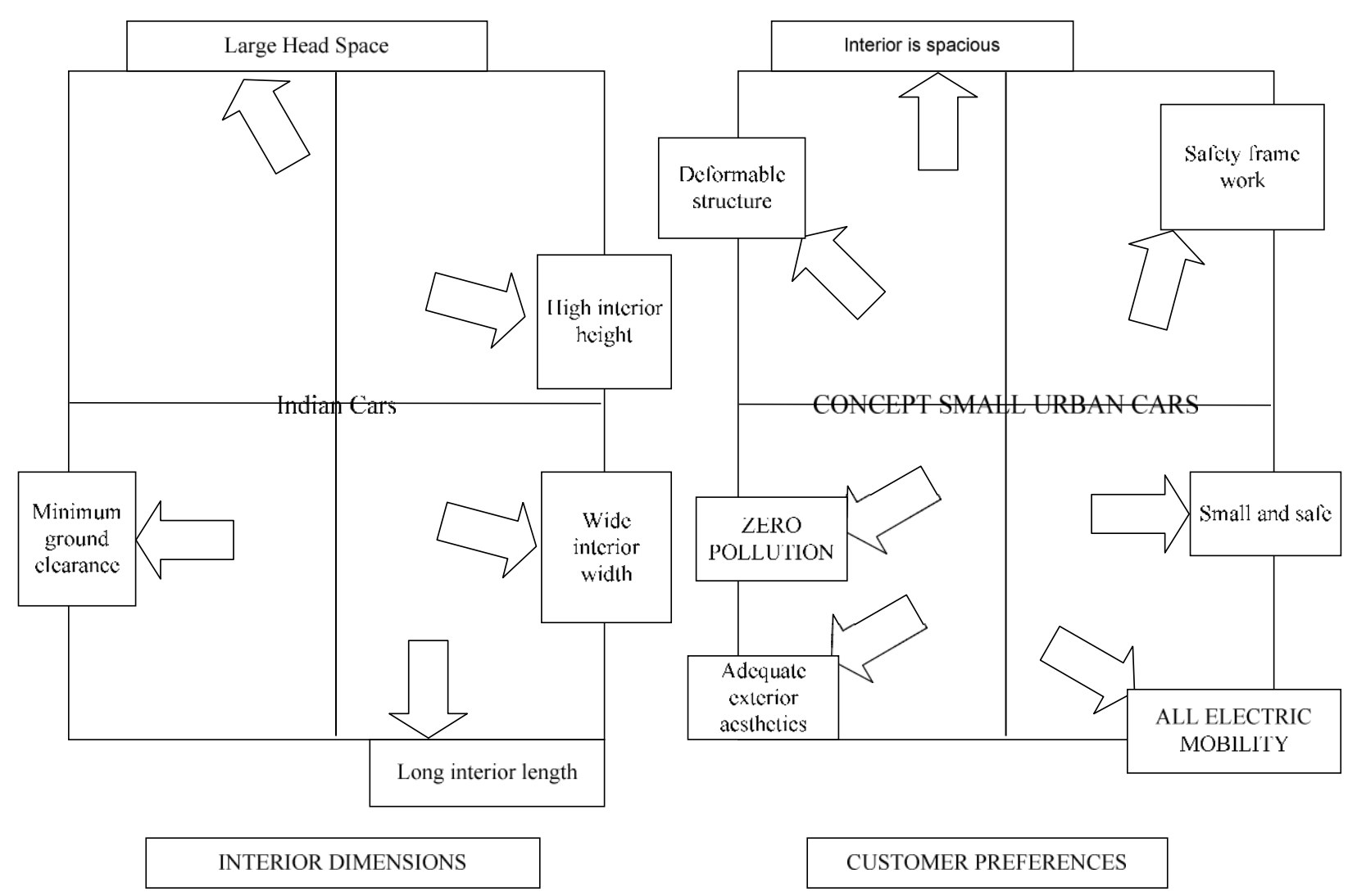

\section{Figure 5: Correlation between interior comfort and Customer preferences}

From the study a deformable structure would protect the occupants in case of impact from the front and reinforcement bars would be added to protect the occupant from the side and back. A limited open design would reduce the structure and exterior would be more aesthetic and interior would have more space and on board comfort. Small devices 
can be activated with the solar panels which are mounted on the sides and top of the car. The suggestible exterior dimensions would be $2150 \mathrm{~mm}$ and width could be 1000 $\mathrm{mm}$.Height could be $1300 \mathrm{~mm}$ and the un laden weight 350 kilograms. Two persons could comfortably ride on the concept car with low cost investment Indian type cars.

\section{Conclusion}

Customer needs and main specifications are a main concern for the future product and the team involved in new product development. This paper proposes a Kano model and need innovation Management and the application of Customer science and Package design concept support method. A systematic representation of the customers needs for new product is arrived at through implicit knowledge and explicit knowledge turning hidden into precise products.

The Kano model classifies the customers' requirements into four divisions; must-be, Attractive, One-dimensional and reverse. Matrix calculations were used to define the design priorities which formed the basics for the future innovative product aesthetics and interior ergonomics with on board comfort.

A relation is established with the Kano model and need profile. The need is identified and Package design concept support method is used to analyze the comfort and aesthetics of a concept car. Certain suggestions are arrived at for the urban commuters and concept cars are formulated. The detailed study suggests that by implementing Kano customer concepts the need of the customer can be easily identified and design is formulated based on the requirements of the customers. The stability of the vehicle, safety, exterior aesthetics and interior on board comfort and ergonomics are obtained.

\section{REFERENCES}

1. Y. Okabe, M. Yamaji and K. Amasaka, "Research on the automobile package design concept support methods "CS-APDM": a customer science approach for vehicle exteriors and package design", Proceedings of the 11th Annual International Conference on Industrial Engineering-Theory, Application and Practice, 2006, pp. 268- 273.

2. K. Amasaka, "Constructing a customer science application system "CS-CIANS”, WSEAS Transactions on Business and Economics,vol. 3(2), pp. 135-142, 2005.

3. Tontini, G., (2003a). Deployment of customer needs in the QFD using a modified Kano model. Journal of Academy of Business and Economics. 2(1), 103-116

4. Morel, L. and Boly, V. (2006). New Product Development process (NPDP): updating the identification stage practices, International Journal of Product Development, 3(2), 232 251 
5. Mulebeke, J.A.W. and Zheng, L. (2006). Incorporating integrated product development with technology road mapping for dynamism and innovation, International Journal of Product Development, 3(1), 56-76

6. Bacon, G.,Beckman, S.,Mowery, D., (1994). Managing Product Definition in HighTechnology Industries. A Pilot Study. California Management Review, Spring 1994, 36(3), $32-56$

7. Kano, N., Seraku, N., Takahashi, F. and Tsuji, S. (1984). Attractive Quality and Must-be Quality. The Journal of the Japanese Society for Quality Control, (April 1984), 39-48

8. Gupta, A., Raj, S. and Wilemon, D.L. (1986) 'A model for studying R\&D - marketing interface in the product innovation process', Marketing, Vol. 50, No. 2, pp.7-17.

9. Headquarters Space and Missile Systems Center (1993) Integrated Product Development Implementation Guide, Los Angeles AFB, CA, March.

10. Koufteros, X.A., Vonderembse, M. and Doll, W. (2002) 'Examining the competitive capabilities of manufacturing firms. Structural equation modeling', Multidisciplinary Journal, Vol. 9, No. 2, pp.256-282.

11. Liker, J.K., Sobek, D.K. and Cristiano, J.J. (1996) 'Involving suppliers in product development in US and Japan: evidence for set-based concurrent engineering', IEEE Transactions on Engineering Management, Vol. 43, No. 2, pp.165-178.

12. Ottoson, S. (2004) 'Dynamic product development', Technovation, Vol. 24, pp.207-217.

13. Phaal, R., Farrukh, C. and Probert, D. (2001) T-Plan: A Fast Start to Technology Roadmapping, University of Cambridge, Institute for Manufacturing.

14. Phaal, R., Farrukh, C. and Probert, D. (2004) 'Customizing roadmapping', Research Technology Management, Vol. 47, No. 2 pp.26-37.

15. Probert, D. and Radnor, M. (2003) 'Frontier experiences from industry-academia consortia', Research Technology Management, Vol. 46, No. 2, pp.27-30.

16. Ramenyi, D. and Sherwood-Smith, M. (1999) 'Maximize information systems value by continuous participative evaluation', Logistics Information Management, Vol. 12, Nos. 12, pp.14-31. 